\title{
A imprensa sul-rio-grandense entre 1870 e 1930
}

\author{
Antonio Hohlfeldt 1 \\ PUCRS
}

Dentre três historiadores que sugerem periodizações para o estudo da imprensa sul-rio-grandense, nenhum atinge plenamente seus objetivos. Francisco Rüdiger fala em dois grandes regimes jornalísticos, o político e o informativo, mas termina trabalhando subperíodos que alcançam, em última análise, cinco diferentes momentos ${ }^{2}$. Elvo Clemente, Jandira M. M. da Silva e Eni Barbosa sugerem três fases, a inicial, a da consolidação e a moderna, mas igualmente subdividem algumas delas em outras sub-fases ${ }^{3}$. Esses dois trabalhos, além do mais, tomam como referências datas que pouco ou nada têm a ver com a própria história da imprensa, em sentido estrito.

\footnotetext{
1 Antonio HOHLFELDT é Doutor em Letras pela PUCRS, onde leciona "Teorias da Comunicação" e "Comunicação e Opinião pública" no Programa de Pós-Graduação em Comunicação Social.

2 RÜDIGER, Francisco - Tendências do jornalismo, Porto Alegre, EDUFRGS. 1993.

${ }^{3}$ SILVA, Jandira M. M. da ; CLEMENTE, Elvo et BARBOSA, Eni - Breve bistórico da imprensa sulrio-grandense, Porto Alegre, CORAG. 1986.
} 
Resta o trabalho curto, mas bem mais abalizado, de Sérgio da Costa Franco que, além de se valer de datas efetivamente vinculadas à história e à evolução da imprensa, não subdivide sua periodização em nenhuma sub-fase, justamente porque seus referenciais são mais objetivos ${ }^{4}$.

Ainda assim, a segunda fase por ele identificada, ponteia entre 1850 e 1912, tendo como parâmetros o surgimento do primeiro jornal civil, o Correio do Sul, de 1852, e o surgimento da clicheria, em 1912. Na verdade, esse período tem pelo menos algumas nuanças que nos levam a considerá-lo sob dois momentos diversos, ainda que parta, evidentemente, de referências da história da imprensa.

Pode-se, assim, começar pelo que se poderia chamar de pré-história da imprensa sul-rio-grandense a partir de 1827, data em que, graças a um decreto de Dom Pedro I, extinguindo a censura, surgiu boa parte da imprensa das províncias, inclusive a do Rio Grande do Sul, com o Diário de Porto Alegre ${ }^{5}$. Sérgio da Costa Franco admite, contudo, ter havido prelos inclusive com anterioridade à independência de 1822; assim, se considerarmos a imprensa em sentido lato, devemos levar em conta esse dado; no nosso caso, em que consideraremos a imprensa em seu sentido estrito, ou seja, publicações periódicas informativas ou opinativas, vamos desprezar o dado. Essa primeira fase se caracteriza pela efemeridade, pela generalizada falta de qualidade das publicações [admitemse exceções, é claro], e pela relação de propriedade/editoria de seus responsáveis, ou seja, o publicista é o proprietário de um prelo e de uma coleção de tipos e divulga, em última análise, as suas próprias idéias.

Se considerarmos, portanto, a imprensa em seu sentido estrito, essa fase se inicia estritamente em 1827 e se caracteriza por publicações precárias e pouco qualificadas, desenvolvendo-se até 1835, quando explode a Grande Revolução;

b) surgiria, em seguida, uma imprensa revolucionária, compreendendo um período anterior à Revolução Farroupilha, entre 1830, mais ou

\footnotetext{
${ }^{4}$ FRANCO, Sérgio da Costa - Evolução da imprensa porto-alegrense in Gente e espaços de Porto Alegre, Porto Alegre, EDUFRGS. 2000, p. 123 e ss.

5 Ver, a propósito, SODRÉ, Nelson Werneck - História da imprensa brasileira, São Paulo, Graal. 1977, e VIANNA, Lourival - Imprensa gaúcha (1827-1852), Porto Alegre, SEC. 1977.
} 
menos, quando se radicalizam os sentimentos revolucionários, e 1845, quando a totalidade dos jornais publicados seguem uma orientação determinada, a favor ou contra os rebeldes;

c) terminado o conflito, organiza-se uma imprensa partidária ou panfletária civil, que vai de 1850 até 1900, pelo menos, quando os proprietários e editores de periódicos se alinham obrigatoriamente a algum dos partidos políticos existentes, já que, sem tal vínculo, era quase impossível a sobrevivência financeira. Contudo, essa imprensa já não é mais exclusivamente partidária. É de se lembrar que, até então, inexistia a publicidade paga capaz de sustentar uma publicação; essa fase começa a ser quebrada com o surgimento do Correio do Povo, em 1895, mas, especialmente, com o cansaço e o desgaste que os partidos políticos sofreram depois da Revolução de 1893;

d) quase simultâneamente, estrutura-se uma imprensa literária, que se inicia ao final da década de 1860 e perdurará ao longo do século XIX e princípio do século seguinte, ainda que com variantes. Esse jornalismo vai dar o primeiro salto de qualidade, possibilitando os grandes jornais da época, que terão menor efemeridade que todos os seus antecedentes - é um dos períodos, portanto, que nos interessa, até porque será marcado pelo surgimento de revistas literárias, de publicações de caricatura e de forte crítica social e, enfim, pela imprensa operária;

e) a imprensa industrial começa com o surgimento da clicheria, em 1912, e perdurará ao longo de todo o século, praticamente até a década de 60 , quando um novo processo, que é a composição a frio da off set passa a ser aplicado pioneiramente pelo jornal Zero Hora, de Porto Alegre. Esse é o segundo período que nos interessa, porque será caracterizado pelo surgimento das revistas para a família e a diversificação das publicações, com a segmentação dirigida às mulheres, aos jovens, às crianças, etc. É também o período em que a competição com outros mídias, como o cinema e, mais tarde, o rádio, fará com que uma forte revisão técnica do jornalismo seja perseguida pelos profissionais de então;

f) a imprensa empresarial, iniciada ainda ao longo do período do Estado Novo, culmina, na década de 70 , com a indústria cultural e a presença dos grandes 
grupos de comunicação. Nesse período, as empresas jornalísticas vão procurar se modernizar cada vez mais, adquirindo maquinário, ampliando a competição entre elas e, enfim, buscando uma crescente aproximação com o seu público, o que vai bem além da simples função jornalística da informação e da opinião;

g) a imprensa de massa se caracteriza pelo que Lúcia Santaella denomina de redes midiáticas ${ }^{6}$, ou seja, a propriedade múltipla, por uma mesma empresa, de diferentes segmentos da comunicação social, como jornal e emissora de rádio, ou de televisão e, mais recentemente, projetos na rede internacional de computadores; esse período, iniciado em torno dos anos 70, ter-se-ia esgotado no final dos anos 90;

h) a imprensa de divertimento, iniciada ao final da década de 1990, encontra-se, evidentemente, ainda em desenvolvimento ${ }^{7}$. Caracteriza-se pelo ultrapassamento da função informativa-opinativa da imprensa, para priorizar a prestação de serviços e garantir boas horas de lazer e entretenimento, levando ao auge aquela quarta função preconizada pelo funcionalista Charles Wright para a imprensa e amplamente assumida pelos demais meios de comunicação social ${ }^{8}$.

Fixaremos nossa atenção nesse período entre o final da década de 1860 até o ano de 1937, quando Getúlio Vargas, o líder todo poderoso do Estado Novo, proíbe os partidos políticos e, por conseqüência, suas publicações, ao mesmo tempo em que amplia fortemente a censura à imprensa e dá novas funções ao DIP9 .

Por que essa datação? O final da década de 1860, como se afirmou, está marcada pelo surgimento de jornais que introduzem o conceito de empresa jornalística, mesmo que alguns deles ainda vinculados a partidos políticos: seus diretores e editores sabem que precisam atender a demandas de seu público, adotando algumas práticas da maioria dos jornais do centro do país, como a publicação de folhetins, por exemplo. Assim é que os encontraremos em todas as publicações, independentemente de sua ideologia. Às vezes, o

${ }^{6}$ SANTAELLA, Lúcia - Cultura das mídias, São Paulo, Razão Social. 1992.

${ }^{7}$ FONSECA, Virgínia Pradelina da Silveira - Jornalismo no conglomerado de mídia. A reestruturação produtiva sob o capitalismo global, Porto Alegre, PUCRS. 2005. Tese de Doutorado. Mimeo.

8 WRIGHT, Charles R. - Comunicação de massa, Rio de Janeiro, Bloch. 1968.

${ }^{9}$ O golpe do Estado Novo estava marcado para 15 mas foi antecipado para 10 de novembro de 1937. 
mesmo folhetim pode ser lido em diferentes jornais, inclusive de orientação ideológica diversa ${ }^{10}$.

O que se observa, assim, é um deslocamento de acentuação, do emissor - um determinado tipógrafo resolve editar um jornal; ou um determinado partido político - para o receptor: mesmo os jornais partidários devem atender a determinadas demandas de seu público, além de divulgarem seus princípios ideológicos. Os jornais vinculados às novas comunidades étnicas - alemães e italianos, principalmente - e aqueles dirigidos ao leitor mais segmentado, seja o intelectual ou a jovem senhora de família, além dos jornais operários, nada mais fazem que enfatizar essa nova perspectiva. É para e com o receptor que os novos editores e proprietários de publicações se dirigem e se preocupam.

É em 16 de junho de 1869 que começa a circular A Reforma, jornal vinculado ao Partido Liberal de Gaspar Martins, e que permanecerá em circulação, mesmo enfrentando a forte repressão do governo de Júlio de Castilhos, após a Revolução Federalista de 18931895, até o ano de 1912.

Em 1856, contudo, já acontecera a primeira publicação literária da província, $\underline{\mathrm{O}}$ Guahyba, devido, dentre outros, ao brummer Carlos Jansen, seguindo-se Murmúrios do Guaiba, em 1870.

Em 3 de março de 1874, estréia o Mercantil, que perdurará até fins de 1897. Ele era originalmente simpático ao Partido Conservador, defendeu a campanha abolicionista, mas se colocou francamente contra a idéia da república e a favor da manutenção da monarquia.

A Federação, fundada por Júlio de Castilhos para ser o baluarte de vitória e de manutenção do poder do Partido Republicano Rio-grandense, é de $1^{\circ}$ de janeiro de 1884 , depois de cuidadosamente planejado. Durará até 1937, quando é extinguido por ato censorial, ainda que já se encontrasse em decadência desde após a Revolução de 1930.

O Jornal do Comércio surge em 1865 e também sobreviverá até 1912, seguindo muito de perto a linha de seu homônimo carioca, tornando-se uma das publicações

\footnotetext{
${ }^{10}$ HOHLFELDT, Antonio - Deus escreve direito por linhas tortas - O romance-folhetim dos jornais de Porto
} Alegre entre 1850 e 1900, Porto Alegre, EDIPUCRS. 2003. 
culturalmente mais importantes da província ${ }^{11}$. Deve-se mencionar, ainda, $\underline{\text { A época, jornal }}$ vinculado à Igreja Católica, surgido em 1887, e que terá importante papel de difusão ideológica em determinado momento da vida política da província, especialmente na luta pela hegemonia republicana contra o Partido Liberal, ao final do século XIX.

Por fim, O Rio Grande, jornal ligado à dissidência republicana, contrária a Júlio de Castilhos, também participará da disputa ideológica do final daquele século, tendo à frente Ramiro Barcellos e Assis Brasil.

Deve-se acrescentar, ainda, os jornais vinculados aos novos grupos étnicos presentes na província, como os alemães, com o jornal católico Deutsches Volksblatt, de 1871; o Deutsche Post, evangélico, de 1880; e, sobretudo, o combativo Koseritz Deutsche Zeitung, de Karl von Koseritz, que se alinha entre os liberais e em defesa dos interesses da colônia alemã (a partir de 1881).

Os italianos, por seu lado, chegados a partir de 1875, já publicam seus jornais desde pelo menos 1883, com o Il Veinte Settembre, de Pelotas; ou L'operaio italiano, de Porto Alegre, a partir de 1899.

A imprensa caricata, de seu lado, estreara com A sentinela do sul, de Júlio Timóteo de Araújo e Manuel Felisberto Pereira da Silva, em julho de 1867, perdurando o jornal durante dois anos, logo seguido por O Charivari, a partir de 1877, dirigido pelo polêmico Miguel de Werna, e que não duraria mais que um ano, ainda que Werna multiplicasse suas

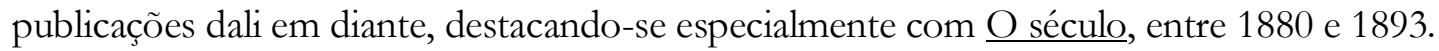

É também de 1869 o início da publicação cultural mais importante da província ao longo do século XIX, a Revista do Partenon Literário, que circulará até 1879, ainda que com pequenos intervalos.

A próxima publicação semelhante será a A Revista do Globo, que começará a circular em torno de 1930, e que perdurará ao longo de mais de três décadas. Essa publicação será uma síntese, na verdade, das revistas literárias e culturais com aquelas de ilustração e de amenidades, cujo sucesso começa em 1912, com a Kodak, graças ao

${ }^{11}$ É ao segundo de uma série de três publicações de mesmo título aquele a que aqui nos referimos. 
surgimento da clicheria, que permite a fotografia. À Kodak, que circula entre 1912 e 1914, seguir-se-á, dentre outras, a Kosmos, que estará presente entre 1925 e 1926, substituída mais tarde, como se disse, pela Revista do Globo.

Desse rápido levantamento, pode-se, então, fazer uma síntese de questões a se discutir sobre naquele período, a saber:

a) uma tentativa de periodização pode indicar uma data de início de um período, uma tendência ou uma prática, mas raramente tem como fixar-se numa data de final de tal período;

b) boa parte dos períodos ou tendências ou práticas, por isso mesmo, se cruzam e são contemporâneas, sem permanecerem exclusivas;

c) o período específico de 1870 a 1930 (com as variantes já indicadas) se caracteriza,

I) pela introdução da imprensa industrial, isto é, com proprietários e empresas jornalísticas que, independentemente de seu alinhamento ideológico e partidário, necessitarão da publicidade e da assinatura do periódico para sobreviverem, ou seja, comportam-se enquanto empresas, buscando lucros além de publicização das idéias e princípios de seus proprietários; até mesmo os jornais claramente partidários, como A Federação, constituem-se enquanto empresas e necessitam de capital a ser integrado por seus apoiadores, bem como de atrativos para os seus leitores, atrativos que devem ir além daqueles vinculados mais diretamente ao partido;

II) pela multiplicação de tendências e públicos a serem atendidos e atingidos pela imprensa, seja do ponto de vista ideológico, seja do ponto de vista da segmentação populacional, devendo-se isso especialmente ao crescimento da alfabetização $^{12}$ e à urbanização da província; assim, à imprensa industrial, em sentido

\footnotetext{
12 Quando da proclamação da república, em 1889, o Rio Grande do Sul possui 72\% de analfabetos nas cidades, e na campanha chega a $90 \%$. Não obstante, o panorama será mudado rapidamente nos anos seguintes, e, de qualquer forma, a taxa de alfabetizados já é suficiente para a multiplicação das publicações na província. Desse final de século, aliás, são a criação da Escola
} 
estrito, soma-se a imprensa partidária, a imprensa literária, a imprensa cultural em geral, a imprensa feminina, as publicações dirigidas às crianças e aos jovens, as revistas ilustradas para toda a família, as publicações de caricaturas e charges e, enfim, jornais e revistas operários e de trabalhadores, além daqueles dirigidos aos novos colonizadores e, por isso mesmo, escritos em seus idiomas de origem;

III) pelo aumento significativo das tiragens e pela estabilidade das publicações: salvo algumas exceções, os jornais e revistas experimentam circulações largas, em termos da época, graças a novas faixas de leitores, recém-alfabetizados ou urbanizados, ou em processo de alfabetização e urbanização, e que passam a ter interesse em tais publicações; como tais periódicos sobrevivem da publicidade e, sobretudo da assinatura, terminam por experimentar uma vida mais longa, bastando lembrar-se, aqui, como referência, jornais bem díspares como o Jornal do Comércio (1865 a 1912), $\underline{\text { A }}$ Federação (1884 a 1937), o Deutsche Zeitung (1861 a 1917), a Revista do Partenon

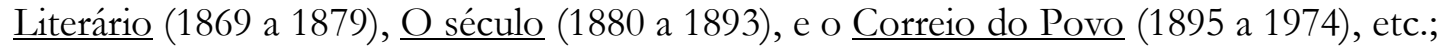

IV) pela prioridade dada ao leitor, à catequese ideológica ou partidária se soma o espaço de lazer e de divertimento, a publicação de cartas de leitores, o acompanhamento da vida cotidiana da cidade, inclusive com denúncias sobre problemas esquecidos pela autoridade, como é o caso da Gazetinha (1891 a 1900), que chega a fazer campanhas contra a prostituição e a favor da abertura e do calçamento de novas ruas no centro da cidade;

V) pela crescente importância dada à informação que, durante a ênfase da imprensa partidária, ainda convive com o proselitismo político-partidário, mas que, a partir da ascensão do Correio do Povo, ganha definitivamente prioridade,

\footnotetext{
Normal e o Ateneu Rio-grandense (1871), o Liceu Rio-grandense de Agronomia e Veterinária, a Escola Prática de Agricultura, a Escola Militar e a Escola Prática de Tática e Tiro. Fechava-se assim o ciclo virtuoso da criação das grandes instituições urbanas, iniciado na década seguinte ao final dsa Revolução Farroupilha, com o Instituto Histórico e Geográfico, o Theatro São Pedro, as bibliotecas Riograndense e Pelotense, bem como a Biblioteca Pública de Porto Alegre. Em 1885, Porto Alegre possui 85 jornais em circulação! Num segundo movimento, o final da década de 1920 terá a Faculdade de Direito de Porto Alegre e a de Pelotas, a Faculdade de Medicina, criada por Protásio Alves, a Escola de Belas Artes, a Escola de Engenharia, etc.
} 
convivendo com os espaços de lazer e de publicidade que igualmente se afirmam nas páginas dos jornais;

VI) pela participação dos jornais nos grandes acontecimentos da época, que encampam e lideram, seja a campanha abolicionista, seja a republicana, às vezes até a radicalidade de defender uma revolução, como ocorreu por três vezes, ao menos, ao longo desse período, em 1893, em 1924 e em 1930; além de acontecimentos extraordinários, como o episódio dos Mucker, em 1874, na localidade do Ferrabrás, em São Leopoldo; ou o do Contestado, de 1915, que acabou envolvendo o estado. Ou seja, os jornais, estritamente partidários ou não, alinham-se junto aos principais debates da nacionalidade;

VII) pela modificação dos formatos e da quantidade de páginas das publicações, notadamente dos jornais que abandonam a forma tablóide e fixam-se nas dimensões standard, o que só será novamente modificado a partir da década de 50 do século XX. Ao mesmo tempo, os jornais ganham corpo, deixando as tímidas quatro para chegarem a 16 ou até mesmo 32 páginas diárias;

VIII) pela continuada e perseverante intervenção das autoridades sobre as publicações, quer através da simples censura ou da perseguição policial, quer através dos assassinatos e dos empastelamentos das redações, como ocorrerá especialmente no decênio de 1890, antecedendo e seguindo-se à Revolução Federalista $^{13}$. O processo, aparentemente superado no início do XX, é retomado com a Revolução de 30 e especialmente com o golpe do Estado Novo; não obstante, é desse momento, a partir da Constituição Estadual de 1891, inteiramente redigida por Júlio de Castilhos, que a liberdade de imprensa é inscrita na carta magna do Rio Grande do Sul ${ }^{14}$.

\footnotetext{
13 Ver, a respeito, RUSSOMANO, Victor - História constitucional do Rio Grande do Sul, Porto Alegre, Assembléia Legislativa do Estado do Rio Grande do Sul. 1976, em especial ps. 261/2, sobre o governicho, e FLORES, Moacyr - 1893-1895 - A revolucão dos maragatos, Porto Alegre, EDIPUCRS.1993, em especial ps. 63, 67, 105, 107 e 121.

${ }_{14}$ RUSSOMANO, Victor - Op. cit., p. 354, com especial referência aos artigos 209 e 212: "Todos podem comunicar os seus pensamentos por palavras escritas e publicá-las pela imprensa em toda a matéria, sem necessidade de censura prévia; ficando, porém, responsáveis pelos abusos que cometam no exercício desse direito, nos casos e pelo modo que a lei determinar" e "Nenhum
} 
IX) pela crença numa espécie de poder mágico das palavras (...) capazes de, por si só, provocarem mudanças na sociedade, conforme um estudioso ${ }^{15}$.

Por tudo isso, pode-se afirmar que o período entre 1870 e 1930 é de radical modificação na história da imprensa sul-rio-grandense, bem como na brasileira, ainda que não se deva falar em ruptura total de modelos ou abandono de certas práticas. Deve-se, antes, citar a convivência, com maior ou menor beligerância, de práticas de tendências préexistentes e que perdurarão durante o período, ao lado de outras tantas que surgem e terminam por se afirmar durante essa época.

Tomemos alguns exemplos para ilustrar nossas afirmações:

- levantamento feito junto aos jornais porto-alegrenses indicou a forte tendência à publicação de folhetins, que começa na década de 1850 e atinge seu auge nas décadas de 1880 e 1890, sendo, nessa primeira década, editados 112 obras e, na seguinte, 73, principalmente textos franceses traduzidos, de tendência romântica. No entanto, à medida em que o gênero se firma no gosto popular, começam a ser divulgados textos norte-americanos, ou mais realistas, e inclusive se abrem espaços para autores locais;

o debate político-partidário existente nas páginas dos jornais sulrio-grandenses coloca o jornalismo local em destaque na comparação com o do restante do país. Assim, sobre A Federação, se escreve ter sido o grande propagandista da república, pois é a partir de suas páginas que Júlio de Castilhos forja a questão militar que terminaria desgastando o trono imperial junto aos militares, mesmo que o golpe de 1889 tenha praticamente marginalizado aos republicanos gaúchos ${ }^{16}$; e sobre a imprensa liberal,

gênero de trabalho, cultura ou comércio pode ser proibido uma vez que não se oponha aos costumes públicos, à segurança e à saúde dos cidadãos".

${ }^{15}$ FÉLIX, Loiva Otero - Pica-paus e maragatos no discurso da imprensa castilhista in POSSAMAI, Zita (Org.) - Revolução de 1893, Porto Alegre, Secretaria Municipal de Cultura, Caderno Porto \& Vírgula.1993, p. 52.

16 Ver, a propósito, RUSSOMANO, Victor - Op. cit., p. 195; FLORES, Moacyr - Op. cit., p. 13 e 16; MORAES, Carlos Dante de - Figuras e ciclos da bistória rio-grandense, Porto Alegre, Globo. 1959, p. 157; SOARES, Mozart Pereira - Júlio de Castilhos, Porto Alegre, Instituto Estadual do Livro, Coleção "Rio Grande político. 1996, p. 65; FRANCO, Sérgio da Costa - Júlio de Castilhos e sua época, Porto Alegre, EDUFRGS. 1996, ps. 46/47 e $48 .$. 
notadamente A Reforma e o Koseritz Deutsche Zeitung, ter defendido fortemente as idéias originais do liberalismo, mesmo contra as posições polêmicas e contraditórias dos Ministérios que se sucediam no Rio de Janeiro, assumindo a centralização da administração imperial, mas, ao mesmo tempo, defendendo os interesses dos grandes setores senhoriais agrícolas e pecuários da província, bem como abrindo o debate nacional sobre o direito ao voto dos não-católicos, defendido por Gaspar Martins ${ }^{17}$;

se levarmos em conta a afirmação de Gramsci, segundo a qual $a$ imprensa integra a estrutura ideológica da classe dirigente, pode-se afirmar que os jornais do final do século XIX expressaram fundamentalmente o pensamento das elites sul-riograndenses, fossem elas conservadoras ou não. O grande debate, contudo, é que, enquanto a imprensa liberal manteve-se presa a tradições conservadoras, $\underline{\text { A Federação }}$ soube perceber os novos segmentos populacionais e urbanizados que surgiam, integrando-os a seu discurso e falando para eles e em nome deles. Daí o sucesso do PRR - Partido Republicano Rio-grandense, ainda que seu domínio da política gaúcha não se deva, evidentemente, apenas a essa prática eficiente;

por outro lado, o final do século XIX assistiu e participou de uma forte disputa entre duas classes dirigentes, aquela antiga, dos grandes proprietários quase feudais da pampa, rurais e aristocráticos, que duvidavam do voto e da capacidade da população, e uma outra, mais vinculada a uma nova ordem surgida com o fim da escravatura, e que precisava incorporar as novas massas populacionais centralizadas especialmente nas cidades. Quando entramos no século XX, o domínio do PRR apenas reflete uma realidade que haveria apenas de se expandir e afirmar, que era a realidade das ruas dos centros urbanos, de Pelotas a Porto Alegre, e de novos segmentos populacionais como os operários e os descendentes daqueles primeiros colonizadores alemães ou italianos, aqui chegados ao longo do século anterior. Pela primeira vez, efetivamente, as lideranças políticas e intelectuais, impulsionadoras da opinião pública, tinham veículos eficazes colocados a seu dispor, o conjunto de publicações da imprensa sul-rio-

\footnotetext{
17 Ver, especialmente, FÉLIX, Loiva Otero - Op. cit. e ISAIA, Artur César - A imprensa liberal riograndense e o regime eleitoral do império: 1878-1900, Porto Alegre, PUCRS. 1988, Dissertação de Mestrado. Mimeo.
} 
grandense. Mais que nunca, aqui, o princípio detectado por Gabriel Tarde ${ }^{18}$ a respeito da formação dos públicos, fazia-se real: as grandes massas, em princípio anônimas, por ação da imprensa, haviam se transformado em um público influente, capaz de decidir por si próprio os seus destinos, como o comprovaria, por exemplo, a primeira grande greve de $1917^{19}$

o último jornal que se pode classificar como político-partidário, em sentido estrito, foi $\mathrm{O}$ Estado do Rio Grande, que circulou de 1929 a 1961, publicação vinculada ao Partido Libertador, que sucedera ao partido Federalista. Na avaliação de Francisco Rüdiger, todo o conjunto de modificações sofridas pela sociedade e a conjuntura político-econômica do estado, e que discutimos acima, influenciou fortemente o jornalismo sul-rio-grandense, que entrou em progressiva crise, ao cabo da qual terminaria desaparecendo(...) As suas condições históricas de possibilidade começaram a se desintegrar, retirando a estrutura necessária a sua reprodução ${ }^{20}$

18 TARDE, Gabriel - A opinião e as massas, São Paulo, Martins Fontes. 1992.

19 Ver, a respeito, BODEA, Miguel - A greve de 1917 - As origens do trabalbismo gaúcho, Porto Alegre, L\&PM. Sem data; e PETERSEN, Sílvia R. F. - "As greves no Rio Grande do Sul - 1890 -1919” in DACANAL, José Hildebrando et GONZAGA, Sergius - RS: Economia \& politica, Porto Alegre, Mercado Aberto. 1979, p. 277 e ss.

${ }^{20}$ RÜDIGER, Francisco - Op. Cit., p. 39. 